Pesq. Vet. Bras. 36(2):90-93, fevereiro 2016

DOI: $10.1590 / \mathrm{S} 0100-736 \mathrm{X} 2016000200005$

\title{
Retrospective study of pre-anesthetic electrocardiogram examination of 700 dogs conducted at the Veterinary Hospital of UFMG (2013-2014) ${ }^{1}$
}

\author{
Ana Flávia Machado Botelho², Maira Souza Oliveira ${ }^{3}$, Benito Soto-Blanco ${ }^{4}$ \\ and Marília M. Melo ${ }^{4 *}$
}

\begin{abstract}
Botelho A.F.M., Oliveira M.S., Soto-Blanco B. \& Melo M.M. 2016. Retrospective study of pre-anesthetic electrocardiogram examination of 700 dogs conducted at the Veterinary Hospital of UFMG (2013-2014). Pesquisa Veterinária Brasileira 36(2):90-93. Departamento de Clínica e Cirurgia Veterinárias, Escola de Veterinária, Universidade Federal de Minas Gerais, Av. Presidente Antônio Carlos 6627, Belo Horizonte, MG 31275-013, Brazil. E-mail: mariliamm@ufmg.br

Pre-operative electrocardiograms performed in 700 dogs were analyzed in order to establish correlation between sex, age, indication for surgery, body condition score, breed and weight. Initially a clinical questionnaire was filled out from each owner, including age, breed, sex, weight, clinical history and surgical indication. Dogs above 6 years of age or those showing any kind of cardiac auscultation disturbances were referred to electrocardiogram (ECG) evaluation. All ECG were performed and analyzed by the same veterinary specialist. Abnormalities at ECG were founnd in 364 of 700 (52\%) evaluated dogs, and the most frequent variation was sinus arrhythmia, observed in 293 dogs (25.4\%). No significant correlation was found between the electrocardiographic alterations with weight, sex and age of the animals. Therefore ECG should be conducted routinely regardless of age, sex, breed or surgical indication, highlighting its value for determining a safe anesthetic protocol that promotes minimal cardiopulmonary depression and allows rapid post-surgical recovery.
\end{abstract}

INDEX TERMS: Electrocardiography, dogs, anesthesia, arrhythmias.

RESUMO.- [Estudo retrospectivo de exames eletrocardiográficos pré-anestésicos em 700 cães realizados no Hospital Veterinário da UFMG (2013-2014).] Foram analisados exames eletrocardiográficos pré-operatórios de 700 cães, com o objetivo de estabelecer correlação entre sexo, idade, indicação cirúrgica, condição corporal, raça e peso. Inicialmente, um questionário clínico foi preenchido

\footnotetext{
${ }^{1}$ Received on May 7, 2015

Accepted for publication on November 30, 2015.

${ }^{2}$ Programa de Pós-Graduação em Ciência Animal, Escola de Veterinária, Universidade Federal de Minas Gerais (UFMG), Av. Presidente Antônio Carlos 6627, Belo Horizonte, MG 31275-013, Brazil.

${ }^{3}$ Programa de Pós-Graduação em Ciência Animal, Escola de Veterinária, Universidade Federal de Minas Gerais (UFMG), Av. Presidente Antônio Carlos 6627, Belo Horizonte, MG 31275-013, Brazil.

${ }^{4}$ Departamento de Clínica e Cirurgia Veterinárias, Escola de Veterinária, UFMG, Av. Presidente Antônio Carlos 6627, Belo Horizonte, MG 31275013, Brazil. *Corresponding author: mariliamm@ufmg.br
}

por cada proprietário, com informações sobre sexo, raça, sexo, peso, histórico clínico e indicação cirúrgica. Os cães com mais de seis anos de idade e aqueles que apresentavam qualquer tipo de alteração à auscultação cardíaca foram encaminhadas para avaliação por meio de eletrocardiograma (ECG). Todos os ECG foram realizados e analisados pelo mesmo veterinário especialista. As anormalidades ao ECG foram observadas em 364 dos 700 (52\%) cães avaliados e a alteração mais frequente foi a arritmia sinusal, observada em $293(25,4 \%)$ cães. Nenhuma correlação significante foi observada entre as alterações eletrocardiográficas com o peso, o sexo e a idade dos animais. Sugere-se, portanto que o exame de ECG seja realizado de forma rotineira, independente de idade, sexo, raça ou indicação cirúrgica, destacando seu valor para a determinação de um protocolo anestésico que promova mínima depressão cardiopulmonar e rápida recuperação pós-cirúrgica.

TERMOS DE INDEXAÇÃO: Eletrocardiografia, cães, anestesia, arritmia. 


\section{INTRODUCTION}

The electrocardiogram (ECG) is the most commonly used examination for the diagnosis of alterations in the cardiac rhythm (Tilley 1992) and has been established as an easy method to be conducted, with low costs and extremely useful for information about the cardiovascular system (Tilley 1981, Ferreira et al. 2008). The examination is indicated when arrhythmias are detected in the physical examination, such as bradycardia, tachycardia or irregularities in rhythm that are not secondary to respiratory sinus arrhythmia. It can also be indicated in patients with a history of syncope, weakness, heart diseases, for monitoring anti-arrhythmic therapy, in cases with suspected pleural or pericardial effusion, and for pre-anesthetic evaluation (Tilley 1992).

The ECG should be conducted routinely in the pre-, trans- and post-anesthetic periods in animals of all ages and weights, regardless of indication for surgery and clinical history (Duerr et al. 2007, Carvalho et al. 2009). The examination is particularly important in elderly patients, due to their higher susceptibility to cardiovascular depression and hypotension, common alterations associated with different anesthetic agents (Menegheti et al. 2014).

In pre-anesthetic evaluation, ECG should be considered a routine examination and mandatory for the anesthetic procedure, used as a guide for choosing the most suitable drugs to be used for each patient (Fantoni \& Cortopassi 2002, Kocatürk et al. 2010). During trans-anesthetic period some complications should be considered, such as cardiopulmonary arrest, hypoventilation, hypotension and arrhythmias, including tachyarrhythmias and bradyarrythmias which require an ECG monitoring to be correctly identified. Tachycardia can be associated with surgical stimuli, hyperthermia and the administration of certain drugs, such as ketamine, while bradycardia can be associated with administration of xylazine, low doses of atropine sulfate, phenothiazine tranquilizers, opioids and general inhalation anesthetics (Slatter 1993, Fantoni \& Cortopassi 2002). Methadone and acepromazine, commonly used during anesthesia, can cause ECG alterations that must be diagnosed. Menegheti et al. (2014) associated methadone, analgesic drug used during trans-surgical period, with the occurrence of bradycardias and acepromazine with risk to develop first degree atrioventricular blockage, T wave elevation or depression as well as morphologic alterations on the ECG waves. Finally, in post-anesthetic period the ECG evaluation is also recommended aiming to closely monitor intermittently arrhythmias or to identify other alterations that did not appear during the anesthetic period, but could happen during recovery, due to residual effects of anesthetics sensitizers of myocardial cells, like halothane (Slatter 1993, Fantoni \& Cortopassi 2002, Duerr et al. 2007).

Considering the importance of cardiac rhythm knowledge to select the most suitable anesthetic protocol to each patient, this study aims to report findings in the pre-operative ECG examinations of dogs referred to the Veterinary Hospital of the Universidade Federal de Minas Gerais. It also intends to determine correlations between the ECG findings and surgical indication, breed, sex, weight, age and clinical history.

\section{MATERIALS AND METHODS}

Pre-anesthetic ECG examinations from 700 dogs were evaluated. All animals were referred to the Veterinary Hospital of the Universidade Federal de Minas Gerais (UFMG), located at Belo Horizonte city, Minas Gerais state, Brazil, from February 2013 to June 2014. Initially a clinical questionnaire was filled for each owner, including age, breed, sex, weight, clinical history and surgical indication. Either animals above 6 years of age or those showing any kind of cardiac auscultation disturbances were referred to ECG evaluation. All ECG were performed and analyzed by the same veterinary specialist. The electrodes were placed in forelimbs and hindlimbs according to Tilley (1992), in right lateral recumbent.

The six frontal plane leads were recorded at a velocity of 50 $\mathrm{mm} / \mathrm{s}$ and sensitivity of $1 \mathrm{~cm}=1 \mathrm{mV}(\mathrm{N})$ and the lead II was considered for analyzes. The equipment used was a thermal printing electrocardiography (Ecafix, Funbec). The evaluated parameters were: heart rate, cardiac rhythm, duration of the P wave, QRS complex, PR interval and QT interval, amplitude of $\mathrm{P}$ waves, $\mathrm{R}$ waves and T waves, and alterations of ST segment, as well as the medium cardiac axis. The reference values used for analyses were established by Tilley (1992). Animals were categorized considering the surgical indication into three groups: soft tissue surgeries, orthopedic surgeries and periodontal procedures.

Statistical analysis of qui-square were conducted for the different variables: sex, age, indications for surgery, body condition score, breed, weight, history and physical signs of cardiac disease, and with the presence or absence of ECG alterations $(\mathrm{P}<0.05)$ for the entire sample of animals and for the most frequent breeds.

\section{RESULTS AND DISCUSSION}

From 700 dogs evaluated, 364 (52\%) presented ECG disturbances with high frequency of abnormalities. The percentage verified by Carvalho et al. (2009), studying pre-operative ECGs, was $46 \%$ of the total of 474 dogs. Among our results, $220(31.42 \%)$ dogs were males and 480 $(68.57 \%)$ were females. Higher occurrence in females were also found by Aptekmann et al. (2010) and Damasceno et al. (2014). In our study, no significant correlation was found between sex and arrhythmias, despite the fact that females had higher number of alterations (68.57\%). On the other hand, Olsen et al. (1999) found a higher prevalence in the males than in females.

The results from the ECG evaluation are shown at Figure 1. In order to be considered normal, the ECG should present normal sinus rhythm, sinus arrhythmia and/or wandering pacemaker, with all waves and segments within the normal reference ranges; any other results were considered abnormal.

The most commonly found rhythm was sinus arrhythmia in 293 dogs (25.4\%), which was similar to data described by Gava et al. (2011). The most prevalent ECG alterations were increase in the amplitude of the $T$ wave, in agreement with Carvalho et al. (2009), and the increase of the $\mathrm{P}$ wave (duration and amplitude), in agreement with Cardoso et al. (2013). The alteration between amplitudes of $\mathrm{T}$ and $\mathrm{R}$ waves, that means $\mathrm{T}>25 \% \mathrm{R}$, could be associated with systemic diseases, hidroeletrolytic imbalances, neoplasias, gastric dilation, septicaemia; respiratory, gastrointestinal and central nervous system diseases (Tilley, 1992). 


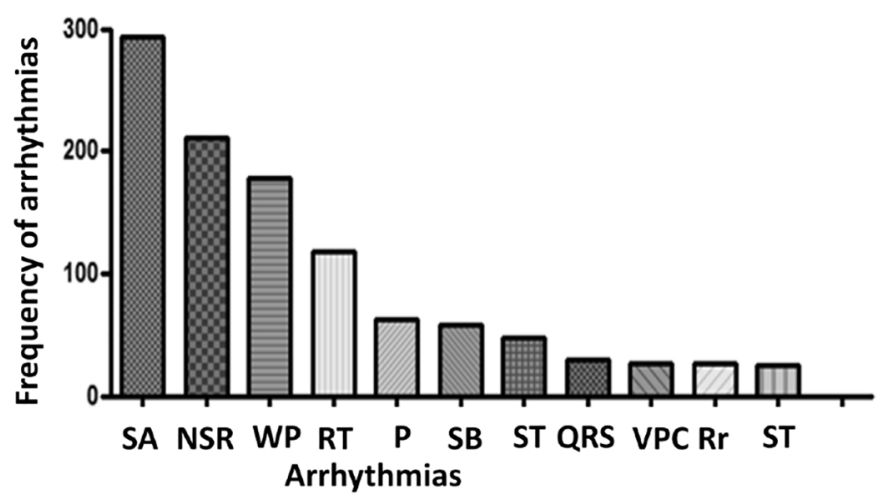

Fig.1. Number of electrocardiographic alterations in pre-anesthetic evaluations of 700 dogs referred to the Veterinary Hospital of UFMG. Graphic demonstrating the frequency of the most common electrocardiographic alterations observed. SA (sinus arrhythmia), NSR (normal sinus rhythm), WP (wandering pacemaker), RT (relation between waves R and T), P (increase in P wave), SB (sinus blockage), ST (sinus tachycardia), QRS (increase in duration of QRS), VPC (ventricular premature complexes), ST (misalignment of ST segment).

The $\mathrm{P}$ wave disturbances could indicate right atrial enlargement, chronic pulmonary disease and atrial overload, generally associated with mitral valve disease which is the most common cardiopathy in elderly small dogs (Atkins et al. 2009, Oliveira et al. 2014). Olsen et al. (1999) conducted a study with Dachshunds and also came to the conclusion that many ECG disturbances can be associated with mitral valve disease especially in older animals.

Arrhythmias such as sinus blockage, atrioventricular blockages and ventricular premature complexes represent

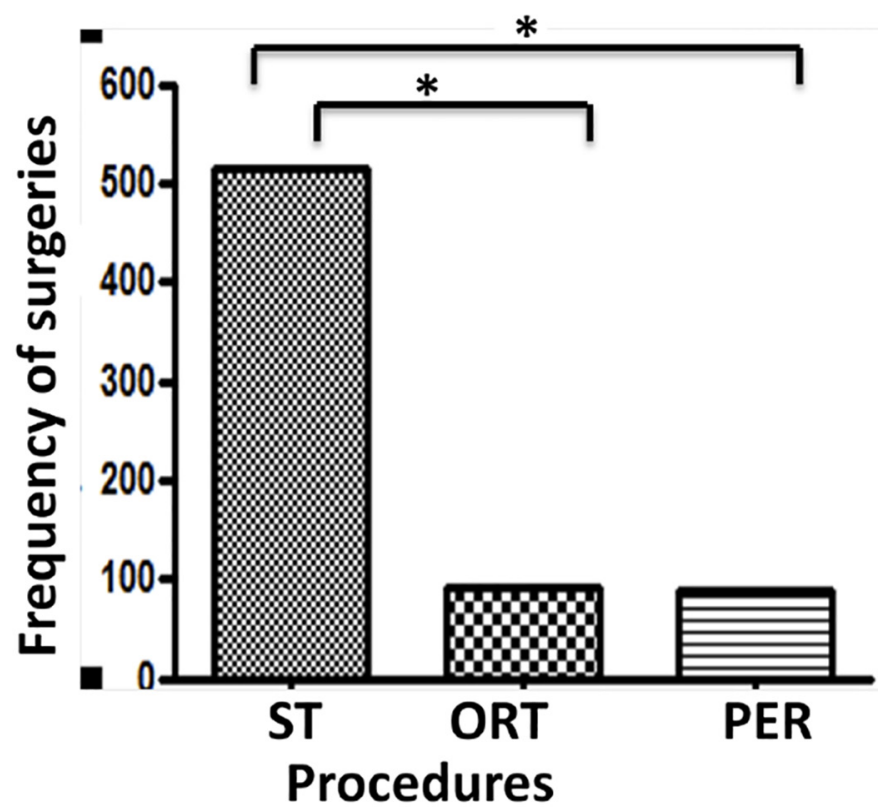

Fig.2. Number of electrocardiographic alterations in pre-anesthetic examinations accordingly to the surgical indication of 700 dogs referred to the Veterinary Hospital of UFMG. Graphic representing the correlation between the surgical indications and electrocardiographic disturbances. ST (soft tissue surgeries); ORT (orthopedic surgeries); PER (periodontal procedures). *Significance $\mathrm{P}=0.0001$.
$9.34 \%$ of the total alterations. These results highlight the importance of using ECG as pre-anesthetic examination aiming to determine the more suitable anesthetic protocol to minimize cardiovascular depression and achieve rapid post-surgery recovery. In animals with these alterations some drugs should be avoided, such as ketamine, xylazine and acepromazine, due to the risk of aggravating arrhythmias. Propofol also should be used carefully since the risk of respiratory insufficiency and cardiopulmonary arrest is higher, especially in patients with heart diseases.

Amongst the total of dogs sampled, only 32 (4.57\%) were previously diagnosed with cardiovascular disease, $50 \%$ were poodles and $93.8 \%$ above 96 months old. Amongst the cardiovascular problems, degenerative valve disease represented $90.6 \%$ of the total and dilated cardiomyopahty 9.38\%. Some kind of ECG abnormality was found in 34.6\% of the cardiac diseased animals, demonstrating the importance of therapeutic interference in these cases, hence the animals were all considered stable and ready for surgery. The ECG is useful in diagnosis and management of different cardiovascular diseases, such as dilated cardiomyopahty and chronic valve degeneration. It was estimated that the higher intensity of the mitral regurgitation increases the possibility of finding electrocardiographic alterations (Soares et al. 2005).

For the sample studied, the most frequent surgical indications were: soft tissue surgeries $73.75 \%$, with $45.49 \%$ being mammary tumor removal; $13.3 \%$ orthopedic surgeries and $12.95 \%$ referred to periodontal procedures. Significant predispositions were observed correlating arrhythmias to certain procedures, in disagreement to Carvalho et al. (2009), as shown in Figure 2. In the present study, soft tissue procedures were more prevalent and these patients had the highest number of arrhythmias $(\mathrm{P}=0.0001)$.

Dogs were also grouped according to their breed, comprising three large groups: Poodles, Mixed breed dogs and other breeds. The most prevalent breeds in decreasing order were: Poodles 27.23\%, Mixed breed dogs 23.54\%, Yorkshire terrier 8\%, Miniature Pinscher 4.92\%, English Cocker Spaniel 3.38\%, Labrador Retriever 3.54\%, Lhasa Apso 3.23\%, Basset Hound 3.07\%, Pitbull 3.07\%, Maltese $3.07 \%$, Miniature Schnauzer 2.15\%, German Shepherd Dog $2.15 \%$, Dachshund 2\%, Rottweiler 2, Boxer 2\%, Brazilian Terrier $1.38 \%$ and others $9.13 \%$. Similar data was also observed by Carvalho et al. (2009), highlighting the high prevalence of Poodle and Mixed breed dogs. Because they represented more than $50 \%$ of the total sampled, these three groups were separately analyzed, as shown in Figure 3. Poodles and other breeds did not differ amongst each other, however Mixed breed dogs presented the lowest number of arrhythmias in comparison to the other groups. This result indicates that Mixed breed animals are probably less likely to have cardiac arrhythmias. This finding could be associated with the fact that mixed breed dogs have fewer genetic disorders when compared to pure bred dogs, such as dilated cardiomyopahty, aortic stenosis, hypothyroidism, epilepsy and portosystemic shunt, all changes that could lead to cardiac arrhythmias (Bellumori et al. 2013).

The dogs were also grouped accordingly to their age: 0 


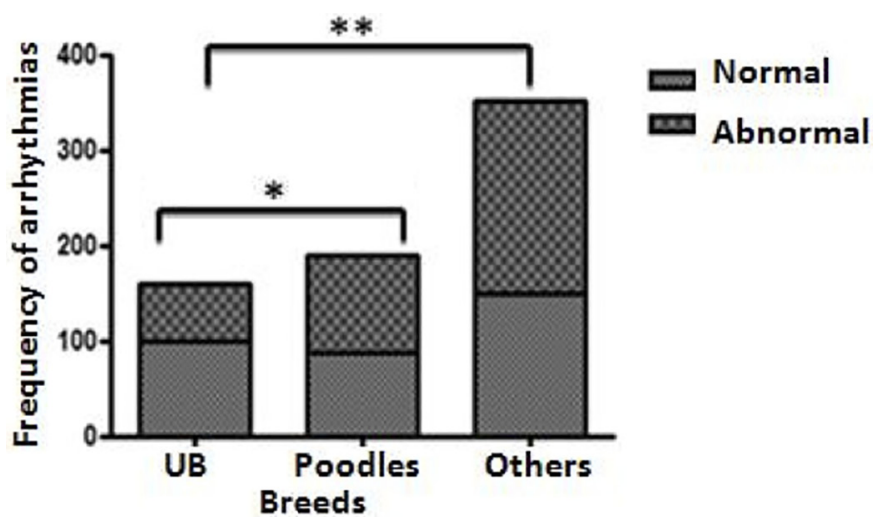

Fig.3. Number of electrocardiographic alterations in pre-anesthetic examinations accordingly to the dog breeds sampled. Graphic that represents the correlations between breeds and electrocardiographic abnormalities. MD (Mixed breed dogs). *Significance $\mathrm{P}=0.0195$, ** Significance $\mathrm{P}=0.0004$.

to 10 months, 11 to 96 months and over 96 months (over 8 years). And they were also classified by weight: 0 to $9.9 \mathrm{~kg}$; 10 to $24.9 \mathrm{~kg}$ and over $25 \mathrm{~kg}$, in view of what described by Carvalho et al. (2009). There were no significant differences $(\mathrm{P}>0.05)$ associating ECG alterations and age groups, reinforcing the importance of this examination in the pre-anesthetic evaluation in animals of all ages and weights, as was determined by Carvalho et al. (2009).

The dogs were considered obese according to the clinical inspection and examination, considering the expected weight for each breed and the age, as well as body fat, detected by inspection and palpation as described by Nelson \& Couto (2001). No significant correlation was observed between obesity and the occurrence of arrhythmias, as also reported by Carvalho et al. (2009).

\section{CONCLUSIONS}

The abnormalities at ECG were frequent in dogs, and the most frequent variation was sinus arrhythmia. No significant correlation was found between the electrocardiographic alterations with weight, sex and age.

It is possible to infer that the ECG is an imperative examination in the pre-anesthetic evaluation, regardless the sex, breed, age, body weight and surgical indication.

Besides, to identify arrhythmias that are often misdiagnosed during routine auscultation, the ECG is of great importance to determine safe anesthetic protocols that promote minimal cardiopulmonary depression and rapid post-surgery recovery.

\section{REFERÊNCIAS}

Atkins C., Bonagura J., Ettinger S., Fox P., Gordon S., Haggstrom J., Hamlin R., Keene B., Luis-Fuentes V. \& Stepien R. 2009. Guidelines for the di- agnosis and treatment of canine chronic valvular heart disease. J. Vet. Intern Med. 23(6):1142-1150.

Aptekmann K., Vailati M., Fortuna T. \& Schwartz D. 2010. Prevalence of cardiac arrhythmias and conduction disturbances in dogs and cats in Botucatu, Brazil (2003-2007). Braz. J. Vet. Res. Anim. Sci. 47(5):371-379.

Bellumori T.P., Famula T.R., Bannasch D.L., Belanger J.M., Oberbauer A. M. 2013. Prevalence of inherited disorders among mixed-breed and purebred dogs: 27,254 cases (1995-2010). J. Am. Vet. Med. Assoc. 242 (11):1549-1555.

Cardoso M.J.L., Melussi M., Zacarias Junior A., Claudino J. \& Fagnani R. 2013. Eletrocardiografia computadorizada em cães da raça American pit bull terrier. Semina, Ciênc. Agrárias 34(5):2341-2348.

Carvalho C.F., Tudury E.A., Neves I.V., Fernandes T.H.T., Gonçalves L.P. \& Salvador R.R.C.L. 2009. Eletrocardiografia pré-operatória em 474 cães. Arq. Bras. Med. Vet. Zootec. 61(3):590-597.

Damasceno A.K.T., Andrade E.N.L., Souza N.F., Meneses A.M.C., Figueiredo M.J.F.M., Corrêa F.C., Almeida J.C.F., Silva A.K.M., Santos B.J.S. \& Pinheiro A.C.O. 2014. Levantamento eletrocardiográfico de cães e gatos atendidos no Hospital Veterinário da Universidade Federal Rural da Amazônia, Belém/Pará, AM. Anais 35o Congresso da Anclivepa, Belo Horizonte, MG, p.75-77. (Resumo expandido)

Duerr F.M., Carr A.P., Duke T., Shmon C.L. \& Monnet E. 2007. Prevalence of perioperative arrhythmias in 50 young, healthy dogs. Can. Vet. J. 48(2):169-177.

Fantoni D.T. \& Cortopassi S.R.G. 2002. Anestesia em Cães e Gatos. Roca, São Paulo. 632p.

Ferreira F.S., Vale D.F., Ramos R.M. \& Carvalho C.B. 2008. Eletrocardiograma na monitoração anestésico-cirúrgica de cães. J. Bras. Ciênc. Anim. 1(2):121-134.

Gava F.N., Paulino-Junior D., Pereira-Neto G.B., Pascon J.P.E., Sousa M.G., Chanpion T. \& Camacho A.A. 2011. Eletrocardiografia computadorizada em cães da raça Beagle. Arq. Bras. Med. Vet. Zootec. 63(2):317-321.

Kocatürk M., Salci H., Yilmaz Z., Bayram A.S. \& Koch J. 2010. Pre- and postoperative cardiac evaluation of dogs undergoing lobectomy and pneumonectomy. J. Vet. Sci. 11(3):257-264.

Menegheti T.M., Wagatsuma J.T., Pacheco A.D., Perez B., Pacheco C.M., Abimussi C.J., Santos P.P. \& Souza Oliva V.N. 2014. Electrocardiographic evaluation of the degree of sedation and the isolated use of methadone in healthy dogs. Vet. Anesth. Analg. 41(1):97-104.

Nelson R.W. \& Couto C.G. 2001. Medicina Interna de Pequenos Animais. $2^{\underline{a}}$ ed. Guanabara Koogan, Rio de Janeiro. 1084p.

Oliveira M.S., Muzzi R.A.L., Araújo R.B., Muzzi L.A.L., Ferreira D.F. \& Silva E.F. 2014. Heart rate variability and arrhythmias evaluated with Holter in dogs with degenerative mitral valve disease. Arq. Bras. Med. Vet. Zootec. 66(2):425-432.

Olsen L.H., Mow T., Koch J. \& Pedersen H.D. 1999. Heart rate variability in young, clinically healthy Dachshunds: influence of sex, mitral valve prolapse status, sampling period and time of day. J. Vet. Cardiol. 1(2):7-16.

Slatter D. 1993. Textbook of Small Animal Surgery. W.B. Saunders, Philadelphia. 2362p.

Soares E.C., Larsson M.H.M.A. \& Yamato R.J. 2005. Chronic valvular disease: correlation between clinical, electrocardiographic, radiographic and echocardiographic in dogs. Arq. Bras. Med. Vet. Zootec. 57(4):436-441.

Tilley L.P. 1981. Basic canine and feline electrocardiography. Can. Vet. J. 22(1):23-25.

Tilley L.P. 1992. Essentials of Canine and Feline Electrocardiography: interpretation and treatment. 3rd ed. Lea and Febiger, Philadelphia. 470p. 